\title{
CLINIC AND PSYCHOANALYTIC PRACTICE WITH PUBESCENTS AND ADOLESCENTS ${ }^{1}$
}

\section{Introduction}

When we intend to order the clinical material of adolescents the first impression we get beyond each patient's uniqueness, is the fact that there is no nosography which covers the diversity of these situations or the one of their daily life. It could be a psychiatric approach, psychopathological or psychoanalysis. It also highlights the fact that any psychoanalytic approach becomes difficult, when the adolescence is not considered as an intersubjective ${ }^{2}$ experience where the endogamous infantile link is in transition towards a link with the exogamous world.

Similarly, I consider their analytical session. I have been mainly inspired on this by authors such as Liberman, the last Meltzer the "bionian" ${ }^{3}$, Piera Aulagnier and the Argentine contributions to the psychoanalysis of the linking configurations. In no way this would mean ignoring the contribution of many other authors of various guidelines who have made and continue making important contributions to the study of the clinic on adolescents. Although all these authors differ with one another in their theoretical frameworks, I privilege those who share the concern of giving answers to clinical situations which they consider experiences shared with the analyst, that the field created at the session will always be an expression of analyzed and analyst, separately and jointly shaping up the field of transference where new experiences take place and where what the past brings up to present is expressed.

Based on an open circuit model for the psychic life, David Liberman ${ }^{4},{ }^{5}$ states that the evolution of the transference in the analytical process is an unpublished, creative fact where both participants are involved, it is not just a repetition of childhood, nor a

\footnotetext{
1 This is the last article written during the authaor's lifetime.

2 In terms objective: linking, where the partaking of the presence of the other is defining and absolutely irreplaceable for the constitution and con tin us complexity of the individual subjectivity and for certain psychic functioning.

${ }^{3}$ Meltzer, D. W: Extended Metapsychology, Edit. Spatia, Bs. Aires 1990

${ }^{4}$ Liberman, D: Lingüística, interacción comunicativa y proceso psicoanalítico Galerna, 1970.

${ }^{5}$ Liberman, D: Lenguaje y Técnica Psychoanalytical, Kargiem an, 1976, p. 73.
} 
return to the first stages through a regression, it is not a reminiscence. He does not see the patient as a child in bond with parental figures represented by the analyst. He criticizes this approach saying: "the patterns of infantile interaction become instruments of a science assistant, an evolutionary psychology which is not the analysis in itself" 6 . He thought that the drives, as well as affective and discursive conditions in childhood, are also present in analysis and not necessarily by evoking the past. "The analysis is not to discover... But to restructure or create and invent"7 (Liberman, D 1970, page 426). Delia T. Aryan considers that this is a second definition of the transference brought up by David Liberman (Delia T. de Aryan) ${ }^{8}$. She adds that Liberman points out that emphasizing the unconscious determinism and intra psychic conflicts within a unipersonal conception limits the understanding of the patient since the personal characteristics of the analyst and their referential scheme are the elements which will decide the direction of the transference in the process. In the analytical process the interaction is a joint creation.

This is the way I see it when I think of it as and inter subjective experience.

In this context, I will take psychoanalytic general concepts relevant to this topic, reconsidering them and applying them to the puberty-adolescence.

\section{Existential problem}

A central issue for the young man coming out to reach exogamy is to know and understand his new reality, both the understanding of himself and his specific problems of any kind that he will resolve day by day; also, the whole understanding of his existence inserted at the time and the world and what is expected of him.

The first important shock and disappointment that triggers the pubertal emotional experience is that despite having foundational beliefs rooted in the certainty of meanings granted by the alleged omniscience of parents, the adolescent will not dispose of meanings fixed somewhere and forever, ready "to be discovered", apprehended and applicable as a technique which can be reached through some dark, bitter and disturbing mastering and at a slow pace realizing that such thing does not exist, that he might not grasp a complete guaranteed and conclusive understanding of the world. This pushes him into hatred or retreat, although there may be moments of maniac

\footnotetext{
${ }^{6}$ Liberman, D: Lenguaje y Técnica Psicoanalítica, Kargieman, 1976, p. 73.

${ }^{7}$ Liberman, D: Lingüística, interacción comunicativa y proceso psicoanalítico Galerna, 1970.

8 Torres de Aryan, D. "La in terpretación en el pen sa mien to de David Liber man" www.apdeba.org / Qué es el psychoanalysis /authors important /rioplatenses. In this important paper the author presents her way of understanding Liber man's thoughts about transference in three stages.
} 
triumphalism.

This is the reason why sexuality is what he is most concerned about, sexuality as a new daily task to which he is fully committed and sexuality as an existential matter. Both conceptions must be taken over by himself. That is to say, no longer in reference to parents, as the essence of the infantile sexuality governed by the Oedipus Complex, but to take over his/her own sexual position (man or woman) as regards his/her body, in the symbolic field.

In 1985 I defined adolescence as "a state of complete significance of the infantile world because two basic elements will be added: the ability to drive the erotic life and the capacity of procreating, both of which will be finally reflected in a sense of identity and autonomy, and the practice of an exogamic social life with an awareness of temporality" (Aryan, A. 1985).

At present, I would add that the sexual drive accompanying this huge psychic work is the psychobiologic effect, felt as an urgency to take action, related to the concerns about self- understanding and understanding the relationship with himself and the world as well.

The uncertainty and confusion suffered by the young affect his capacity to think and clearly convey his demands, as well as knowing exactly what and how to understand and interpret in what is perceived. This situation is reflected in an impressive way in the analytical session. The illusory omniscience awarded to parents, which he considered to be an heir to, collapses when he discovers that his existing in the world as well as having an original possibility with the totality of the meanings and functions is not enough, but it depends on the circular structure of his relation with the understanding. This means, that although things are provided to him with a meaning and a role they already bring along, without knowing it he will understand such things just when inserting them in a context which on the other hand, he will not end up framing properly.

The adequate contextually is directly related to the link between the notion of meaning and its instrumentality. This fact also pushes the young man to the almost compulsive experimentation in search of meanings. He discovers that everything stands as an opening and a possibility. He also discovers that he himself is present in the world as a draft, subject to all type of developments and changes. That he should permanently elaborate the constituent relationship with the world constituting him. These living and existential discoveries, as they are not totally subject to his will and 
conscience, also take him to manipulate the knowledge and interpretation of things, as well as their instrumentality. Then he tries to separate himself from what he finds around and transforms it into an object he can be the subject of, trying to control it by "getting to know it".

In the analytical situation these circumstances are deployed in the reception and transmission of messages where the youngster is mainly concerned about the way to designate the facts and how to locate himself regarding the interpretations that will come up. However, the particular point in this exchange is that the youngster speaks or expresses himself, without knowing what he is transmitting and is totally unaware of the fact that he wants to do it. At that moment he only feels the impetus to control and manipulate information. Sometime will pass until he feels the confident enough to "associate freely".

In order to sustain this characteristic of analytical dialogue it is important that the analyst when listening through his floating attention structures within the manifested significant, a second signifier he will assign a semantic dimension to. This signifier will give the intervening analyst the possibility to let the patient know what he meant without his awareness.

Due to these multiple characteristics of understanding and communicating, analyzing and to be analyzed appear as complex activities. As both involve a lot of unconscious experience any of the participants can contribute to the failure of the objectives of the dialogue if the extreme sensitivity of the steps of these operations is not seriously considered. It is a unique band and exchange namely crafts work. It is not only affected by the amount of sharing of codes according to the seriousness in each case, but also by the personality of the analyst, the degree of their experience and particularly the framing and the personal style offered. As regards this topic the contributions of the Argentinean School, Liberman at first and presently psychoanalysis of the linking configurations is invaluable ${ }^{9},{ }^{10},{ }^{11},{ }^{12}$.

\section{The practice}

During my clinic practice which is also extended to adolescence I have always found M. Klein's affirmation true. She states that "the difference between our methods

\footnotetext{
${ }^{9}$ Liberman D. y Labos, L.; Fantasía Inconsciente, Vínculo y Estados Psicóticos. Kargieman, 1982. Pág. 157

${ }^{10}$ Beren s tein, I. and Puget, J.: Lo vincular. Clínica y técnica psicoa n alítica, Buenos Aires, Paidos 1997

${ }^{11}$ Revista de A.A.P.P.G. en su 45 a niversario: La Perspectiva Vincular en Psicoa $n$ álisis, Buenos Aires, 1999

12 A.A.P.P.G. en s u 50 a niversario: Pensamie $n$ to Vinc ular, u n recorrido de medio siglo, Buenos Aires, Edic.Del Candil, 2004
} 
of analysis [of children] and analysis of the adult is purely technical and not of principles and we reach the same results. The only difference is that we adapt their procedures to the mind of the child ". (The underlined words belong to me) (Klein, M. ${ }^{13}$ Psychoanalysis of Children, Edit Paidos, p. 34).

So that paraphrasing her, I say that the study of the mind of the adolescent will show us the right way for the adaptation of the analytical procedures to make them accessible and therapeutic to early youth.

From the psychoanalytical point of view, it can be considered that the mental state of puber/ adolescent is that of confusion of the temporal-space categories which unable him to organize the positioning of himself and the other. In order to study the final structuring of the mental apparatus (and the various psychic disturbances), it is crucial to carry out a careful study of the imbrications (interplay) between the narcissistic object relation, dyadic, and the triangular situation set by the Oedipus Complex. This approach addressing the clinic is also consistent with the psychoanalytic therapeutic target which is causal and not descriptivephenomenological of symptoms or organized through syndromes.

\section{Analytical attitude in the clinic with adolescents}

In our environment, during the 80's it was still common to consider as an ideal analyst the one who best resembled a screen of the projective identifications of the patient. Thus, he had to seek a "neutrality" to achieve greater control of the therapeutic process, only through verbal interpretations pronounced with the highest serenity and neutral pitch possible.

Such approach intended to assimilate the analytical experience to the scientific principles of modernity and in particular the positivism - the paradigm of hard sciences- where the model of understanding of the analyzed/analyst relation, was the one of an observers exploring an object of knowledge, in a relationship of mutual outsiders. It was stated that the personality of the researcher-analyst did not have any effect on what he was observing and understanding, furthermore, any kind of effect was considered an indicator of pathology of the patient or inexperience and limitations in the side of the analyst. Freud himself, a typical representative of modernity, idealized this model, of absolute force at his time. His insistence $(1912,1913)^{14}$ on abstinence,

\footnotetext{
${ }^{13}$ Klein, M., (1926) "Th e psychological Principles of early a n alysis", in Love, guilt and reparation and other works, Lon don, Hogart h Press, 1975.

14 Freud: Papers of Technique: "The Dynamics of Transference" and "Recommendations to physicians practicing
} 
neutrality, anonymity, objectivity, etc. from the analyst were to keep observer and observed apart. In this way "the inside of the session" had to be kept the most stable and conditions "as objective as possible" to study or explore the unconscious, the only "object" under study in the psychoanalytic session ${ }^{15}$.

Based on this scientific-ideological position, the central concepts of the practice transference, repetition and resistance respected those two independent spaces, each with its psychic character, corresponding to its designed: role object of cognition/expert subject, transference /counter transference, repetition/projective screen, resistance/resisted truth. And interpretations of the analyst had to be exclusively verbal expressions referring to unconscious fantasies gathered in a filedeposit of the analyzed. The omnipotence granted to the explanatory capacity of the theories was such that the psychoanalyst sustained he could provide a position close to certainty.

I would anticipate that as far as I could learn, Freud spoke of the rule of... principle of... abstinence, not of neutrality as a concept. He alluded rather to counter transference situations such as "therapeutic pride", "educational pride" where his operative recommendation could be understood as neutrality. In Vocabulary de Psychoanalyze of Laplanche and Pontalis ${ }^{16}$ we read: "the neutrality does not allude to the real person of the analyst, but to his role". So, an analyst may (and in the case of adolescents it is advisable to do so) adopt any attitude and perform any act, as long as it proves useful to the place and role of the analyst.

The paradigm of the positivist objectivity could be maintained while only the psychic reality of the analyzed was considered, with free association and the analystscreen in floating attention. That is to say that the analyst's abstinence resided in not giving the patient instructions such as to collect his memories or to think of a certain period of his life and not conveying his religious, moral and social values. Obviously, this went to extreme situations as literalizing such rich concepts as "analyst without memory and without desire" (Bion) ${ }^{17}$ or disregarding others as "maternal révèrie" $(B i o n)^{18}$, "the analyst creates the setting with the patient" (Meltzer) ${ }^{19}$ or "transitional

\footnotetext{
psychoanalysis" (1912), SE vol. 12 page 97- 120 and "On beginning the treatment" (1913) SE vol 12, pp. $121-144$.

${ }^{15}$ But Freud himself, who always $h$ ad an absolute faith in science and the conviction that the scientific man would finish dominating, not only the nat $u$ re but also the ma $n$ himself, towards the end of his work understood the psychic reality as a much more complex era (Freud, 1937).

${ }^{16}$ Lapla nche, Jy Pontalis, J B: Vocabularies de la Psychanalyses, Paris: Presses Universities de France, 1968.

17 Bion, W. Attention and interpretation (1970), chapters 3, 4, 5 , 6, 7, 12. New Cork: Basic Books. Cogitations (1992,

${ }^{18}$ Bion, W. "Reverie $\mathrm{m}$ a tern a" en Learning from experience, chapter XII $\mathrm{n} 9,10,11$ y note $\mathrm{n}{ }^{\circ} 5$, (I am thankful to Lic. Marta Martinez for her bibliographic searching of these two concepts of Bion).

${ }^{19}$ Meltzer, D: "The psycho-analytical process", chap. VIII, London: Heinem ann 1967
} 
space and transitional objects" (Winnicott) ${ }^{20}$ and many other concepts, considering them environmentalists or behaviorists.

As a matter of fact, when this conception was extended to children and to pubescent and adolescents, M. Klein's recommendation quoted above was being forgotten, as he stated that the difference between the analysis of a child and of an adult is purely technical and not of principles and that the only difference is that we adapt its procedures to the mind of the child. That is, the invariant constitute the psychoanalytic principles and we must adapt the procedures to the mind of the child and not the child to the procedures. On the other hand, it is thus implied that the classic technique was conceived and refined for the transference neuroses of adults and we need a meth psychological study of the adolescent mental state which constitutes a mosaic of neurotic, perverse-polymorph and psychotic operations in permanent movement.

Trying to cover the diversity of these clinical situations, which are a consequence of the multiple and variable mental state of the pubescent and the adolescent, it is desirable to understand the psyche as an open system and to have an analytical attitude guided by the conceptualizations and ideas of the theory of complexity, which considers the one and the multiple, where the paradox, uncertainty, the fate will always be present such concepts which become absolutely necessary during the development of the adolescent's claim of omnipotence and omniscience: the fact that nothing is unanimous nor definitive, that there are situations with no solution at all, that not everything is guaranteed and that not everything is predictable. The analysis is not only based on the events of childhood in order to avoid repetition. Our knowledge about the unconscious fantasy and the mechanism of projective identification proves useful yet insufficient in order to grasp a clearer understanding and comprehensiveness of the vicissitudes of the psychic reality not entirely located in the single subject, and of the fact that his forced exit to the external world, bears the presence of another one fixing the limits for him. By joining his peer group, the teenager will have the opportunity to slowly realize that he cannot reduce the presence of the other in the bond to the fantasy he has of such person. In those links he will alternately rehearse different roles one by one, the one of the leaders, the close friend, the opponent, the submissive, the marginal and others, assuming some and delegating others. He will leave behind part of his own infantile ideals and take distance from the primary objects of identification

\footnotetext{
${ }^{20}$ Winnicott D.W: (1953) "Transitional objects and transitional phenomena", in Through pediatrics to psychoanalysis, chap. 18.
} 
and will create new meanings among his present links which will produce subjectivity. The rest of the members in his group will make him go through his own draft of historization again and again and they will increase the complexity placing him not only in his drive structure, but also in the linking structure he belongs to. Different kinds of DES- identifications and reidentifications will take place constituting himself and the others. Only this way he will be able to take the definition of his sexual position on himself, sorting out the issue of his drive in the field of symbolism.

\section{Place, function and position of the analyst of pubescent and adolescents}

In my Introduction I explained that I consider any psychoanalytic approach extremely difficult unless the adolescence is taken into account as and inter subjective experience. The prospect of "linking" psychoanalysis along with the contribution of some other authors of different theoretical guidance "props me up" in my practice. I think my tools and qualifications must be proportional to the diversity of the subjective states of the teenagers.

First of all, I think that the analytical encounter must have as a background the irreducible difference between the fantasy they have of each other and what the encounter actually produces for both pubescent and analyst. No doubt obviously the place of analyst imposes the role to contain this difference, that is to say, once the analyst leaves behind the surprise he may go through at a certain moment he must sustain the abstinence and discrimination of the difference at stake. This difference will cause an effect in each again and again contributing to the process of desidentification and production of new subjectivity. It is the framework of subject, link and everything cultural represented by the other.

So, the effort of the analyst from the first interview will be to listen to the youngster and his relationship with his unconscious, and in turn work, infer and eventually operate with the linking plots.

\section{With the pubescent}

The outbreak of puberty is extremely traumatic both in its somatic and psychic aspects, and requires the confirmation and inter subjective propping of the analyst. In the puberty new problems arise but not clear solutions. The analyst's "attitude of listening" is therefore extremely important as it moderates the mistrust and facilitates the pubescent need of idealization of the object, his need for loving and to be loved as 
a whole.

Both the sexually matured body and the narcissistic identifications with the parent of the same sex as a holder and prop up before starting with the oedipal rivalry with him, puts the youngsters in contact with phantasmagoric experiences with no language where the presence of the analyst will become very important. Due to this they seem to be going through borderline situations. In terms of $\mathrm{P}$. Aulagnier, new pictograms need to be covered with fantasies and put into circulation by representations which at the same time when put in contact with the language in the Preconscious stage, will enable the expression of the oedipal rivalry and the one of heterosexual desires (image).

But if the sexual maturation of the body is too traumatic because of the difficulty in its figurability, the symbolization process will stop before the novelty and the complexity of the mental apparatus will take vicarious ways and it will be inexorably shaped into a mosaic of infantile, latent and adolescent aspects.

In his important lack of words or expressions, the pubescent will need the analyst not only to give up his maniac defenses of latency pseudo-maturity ${ }^{21}$, but also to find the necessary words to emotionally sustain his speech during the elaboration. This is not repressed; it needs to be constructed. Thus, the analyst will not only have the task of interpreting, linking causality between an experience of the past and the transferencial experience, but also and especially, he will have to create the space for figurability for new, psychic and somatic appearing novelties. This means, acts of word, sometimes mumbled the closest possible to the first representations of the corporal thing and to the pictographic representations as a minimal psychic activity with which the youngster imagines the state of necessity undoubtedly suffered by both his body and psyche since the earliest stage of childhood. Due to such emotional impact, if the early suffering has been excessive, a fantasy as causal interpretation will not be able to be interposed as to what is happening in his body. The representation of the painful affection accompanying the new and unexpected corporal events, including accidents and surgeries cannot be attributed to anyone's desire and will be the reason for demorphophobia. Hence the fragility, helplessness and mental pain we often observe in the clinic. In this function of figuration creator, the analyst will also need his counter transferencial emotional registry and his intuition.

21 Meltzer, D.: "The relational of an masturbation to projective identification" IJPA vol. 47, pages 335-342. Also, in Sexual states of mind, Parts hire: Clune Press, 1973 
P. Aulagnier 22 thinks that we are unaware of the fact that we have some blanks in our thinking, the mark of some scars where nothing will be ever written on. While they are only few, we can ignore them, but if they cross certain threshold, they manifest themselves as a kind of inhibition. If these blanks are multiplied and concern to sectors where the body, the pleasure and desire are thought of, parts of those sectors will be excluded from the person's thinking and thus he will not be able to make use of those parts with his body, associated with his pleasure and his desire. This is the temporary mental state of the pubescent which does not enable him to make up stories threaded around his corporal new figure with his desires and pleasure as causes.

In the case of very inhibited pubescent or adolescents with turbulent and rugged life, the proposal of a dialogue, conjectures and confrontations in this respect. have proved really useful. I think that to accompany the patient is not only making use of the thought and the affection, which go together, but also of the erogenous body of the analyst. In addition, considering the associations (verbal, graphic material and repeated acting's), floating attention and interpretations, each time that allusions regarding the pubescent daily life arise, I propose to discuss it and to see what comes up. Needless to say, I accept the patient's proposals, always based on the premise of facing together what might emerge, with the aim of tolerating the surprising facts... These are moments of dialogue between two people. A bond in which ideas are discussed, two people see what they can do together when facing an obstacle which disrupts both patient and analyst. And open space to multiple verbal, gestural and corporal discursive acts that can arise in both the analyzed and analyst. Sometimes as staging's and others like performances ("acting out") that, in the limits of analysis, demand our understanding and interpretation, with the intention of getting into the process instead of transforming themselves into passages to the act (more or less surprising dropouts of treatment). It is a dialogue which does not admit the serious silence of the analyst and the classic question "....and what did you think about it?" we would make to the neurotic adult. The pubescent needs a permanent dialogue, a conversational situation similar to the one of playing with the child in the games' room. It is the aspect of the analytical space built up between two, where the causes of all the possible stories will be found and the moment will come when the unconscious shared experience will become conscious.

I believe that the analyst is not only a screen of projections, but he may also get

${ }^{22}$ Aulagnier, P: "The purposes of suffering”, Conf. n.3. APA, Bs. Aires 19, Nov 1981 
involved and at the same time show himself as another different. There is no analysis if there is no bond. There is no bond if the analyst does not show as another. The subjectivity of the analyst is therefore at stake in the treatment. He is another one who may allow modifications on himself by working with the patient although in a different way because his subjectivity participates with abstinence and certain criterion of involvement. At this point of course taking absolute care of the abstinence, when following the script of the other. The analytical positioning is crucial, as the image, the voice, the gaze, are at stake and that is actually the drive in his permanent driving in transference. It is the body of the analyst in act that may slide to the megalomaniacsuperego attitude and action or educational action.

Summing up, it is easy to conclude that the implementation of the concepts of transference neurosis and technical tools will not be enough to deal with them, starting from the hypothesis that, similar to the pre- oedipal period, the mental state of the teenager is a chaotic combination of all the psychopathological categories in permanent movement and emotional instability, by the "breach" of the pseudoadulthood of the latency and the resurgence of uncertainty as regards multiple differentiations (internal-external, adult-child, good-bad, and male-female) within the framework of the disappointment and unbelief of parents. This state of complete remeaning of the infantile world, to which he adds the ability to conduct his erotic life and the ability to pro-create, needs a second reverie, for which the design of psyche as an open system renders crucial, where the drive is constituted in the field of the other and the subjectivities consolidates itself in successive inter subjective experiences where the youngster will metabolize the effects of new relationships outside the shelter and compensation offered by his parents and is now in charge of the new bonds which with a density of their own, write a new history with him which will be different and will also belong to him.

This perspective changes the idea of transference; it would not only be the pattern of transferences-counter transferences. David Liberman thought there are facts and situations which are not transferencial re-editions but arise from the psychoanalytic interaction and are especially triggered by the real person of the analyst and his referential schemes. (Joel Zac Apdeba. 1985 1, 2, p. 28,). The analytical situation proposes a scene which in spite of containing and unfolding the unconscious fantasy, has never taken place before. The transference or better said, what is transferred is contained in the bond with the analyst, being this one of the 
components of such tie... Another component of the bond is the area we might call "free of transferred past", "virgin" opportunity of the present in which there will be something new, not entirely predictable. This opportunity which will give way to a new experience may or may not be significant for both the analyzed and the analyst as it usually happens with any other experience... Therefore, it will also institute the unconscious. In this way the originally can be thought of not only in the infantile, but also in each significant situation for the subject, which can build up the unconscious.

As I see it, this may also be considered as installing counter transference and contributing to the development of the transference. Until now we have referred to counter transference as the reactivated past of the analyst, as well as the experience lived with the analyzed, in the present. On the other hand, working on the linking tissue and on the relationship of internal objects also contributes to the evolution of the transference-counter transference, working with the creative possibilities of the bond. The understanding of the aforesaid has led me to the decision of not adopting an exclusive type of setting, which does not mean I promote thoughtlessness and carelessness within the change of meaning in different kinds of treatment ${ }^{23}$.

Being consistent with Liberman I can see it as the prospective dimension to the transference relationship.

\section{Refrences}

Aryan, Asbed (1985). "Adolescence: Contributions to the methapsychology and psychopathology" Psychoanalysis, APdeBA Review \#3.

Aulagnier, Piera: (1981). "The purposes of the suffering", conference number 3. APA, Bs. Aires 19 November.

Bauman, Zygmunt (2002). Liquid modernity, Fondo de Cultura Económica de Argentina S.A., Buenos Aires.

Bion, Alfred (1977). Green, André: Narcissism of life and narcissism of death, Heimann, Paula: Introjection and projection in the early childhood. Kohut, Heinz: Analysis of self, Buenos Aires, Amorrortu, 1977. Lacan, Jacques: Stage of the mirror.

Liberman, David (1970). Linguistic, communicative interaction and psychoanalytic

\footnotetext{
${ }^{23}$ It is not useless to make it clear that I do not consider "setting" concept only from the point of view of the amount of session s per week.
} 
process Galerna, 1970.

Meltzer, Donald (1968) The psychoanalytic process, Buenos Aires, Hormé, 1968.

Extended Metapsychology

Racker, Enrique: Psychoanalytic technique

Torres de Aryan, D.: "The interpretation in David Liberman's thinking" www.apdeba.org/Quéeselpsicoanálisis/autoresimportantes/rioplatenses 